\title{
A NURBS-based solid modeling to enhance rapid prototyping in the restoration of decorative elements
}

\author{
Michele Cali ${ }^{1}(\mathbb{D})$ Salvatore Massimo Oliveri ${ }^{1} \cdot$ Placido Cali $^{2} \cdot$ Rita Ambu $^{3}$
}

Received: 12 March 2020 / Accepted: 7 October 2020 / Published online: 24 October 2020

(c) The Author(s) 2020

\begin{abstract}
In this research, we describe a computer-aided approach to improve the reconstruction method of decorum in architectural surfaces and sculpture. The effects of withdrawal caused by catalysis of mold in silicone was evaluated and simulated by a NURBS-based solid modelling. A tolerance analysis model was developed to predict manufacturing precision levels. In particular, differential increment along three dimensions was performed considering different volume distributions. The methodology was validated by experimental data obtained during the coffered ceiling restoration of Teatro Massimo Vittorio Emanuele in Palermo. The proposed methodology allowed the reconstruction of decorations or fragments of decoration with high accuracy.
\end{abstract}

Keywords Restoration techniques · Geometric dimensioning and tolerancing · Withdrawal - Silicon mold · Reverse engineering

\section{Introduction}

The reconstruction of decorative or sculptural parts which are partially or totally missing and the reproduction of these pieces in appropriate and accurate proportions can be said to be one of the main problems in sculptural-architectural or archaeological restoration fields [1,2]. This is especially true for fragments to be inserted with high precision, in size often from tenths of a millimeter to few millimeters, in shortcomings artifacts. The $3 \mathrm{D}$ reconstruction through modern rapid prototyping (RP) processes is not always suitable (i.e. decorative parts or sculptor cannot be reproduced in casting material

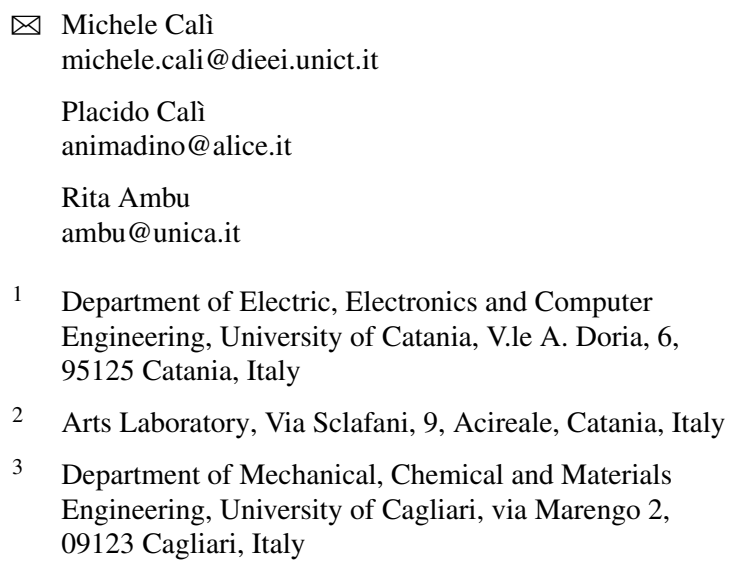

3 Department of Mechanical, Chemical and Materials Engineering, University of Cagliari, via Marengo 2, 09123 Cagliari, Italy 


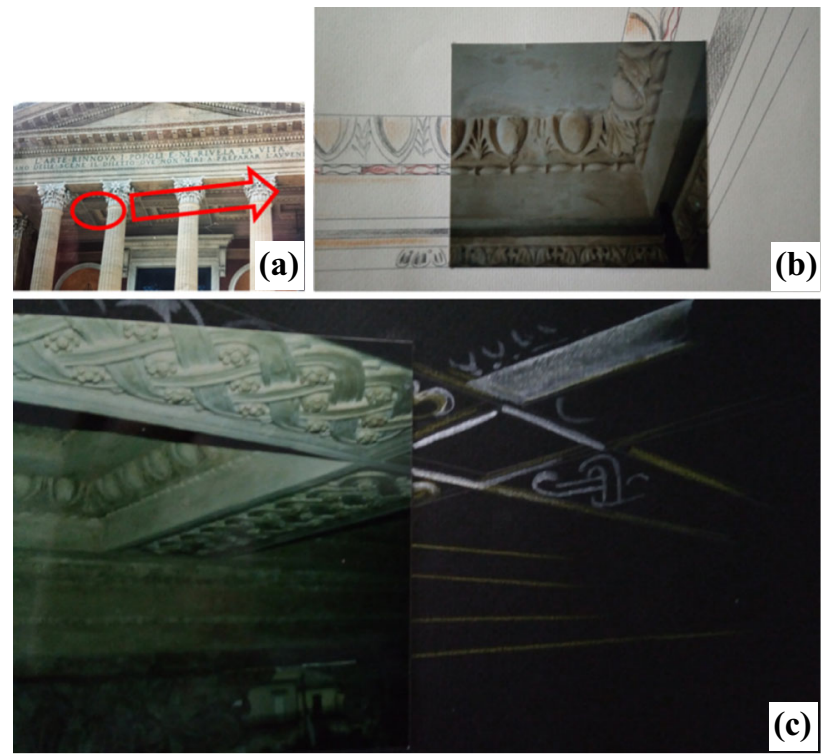

Fig. 1 Decorative elements crumbled or detached in coffered ceiling of Teatro Massimo

\section{Materials and methods}

The intervention of architectural restoration on coffered ceiling is consisted in the replication of decorative elements partially crumbled or detached from roof due to humidity and water infiltration (Fig. 1). In particular, Fig. 1a shows the south-west area to the coffered ceiling where the major lesions of the decoration were present. In Fig. $1 \mathrm{~b}$ the parts of the decoration totally absent in this area are drawn in red.

The detached decorative fragments have an elongated and drop shape arranged continuously along the perimeter of the coffered roof. The ornamental elements of the roof were originally handmade with quite brittle scagliola plaster which can be distinguished for high permeability and vulnerability that permit to absorb the excess moisture and water ingress. Gypsum-based sculpure is typically used to make complex solid shapes in the castings process. The casting scagliola result preserves all the smallest details of the original piece, providing white colour and drying in a very short time, hardening after 30 min depending on the humidity of the environment. Thanks to its good adhesive properties the scagliola can be easily worked and also used to properly shape particularly large smooth surfaces giving the idea of marble, white or aged according to the type of coating. The scagliola can be applied with water, glue and possible coloured pigments. The result is a soft dough poured into a mold with a reinforcement of hemp fibers which increases its hardness and resistance. The performed architectural restoration on coffered ceiling through the traditional method provides that the architectural decoration reproduced in the clay is larger than the original model. This is in order to create a silicone rubber mold which, (a)
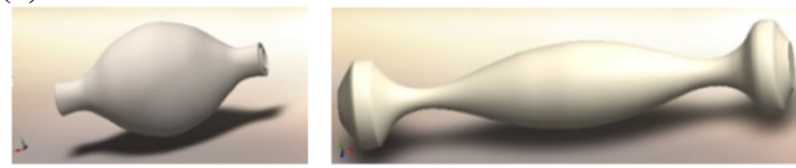

(b)

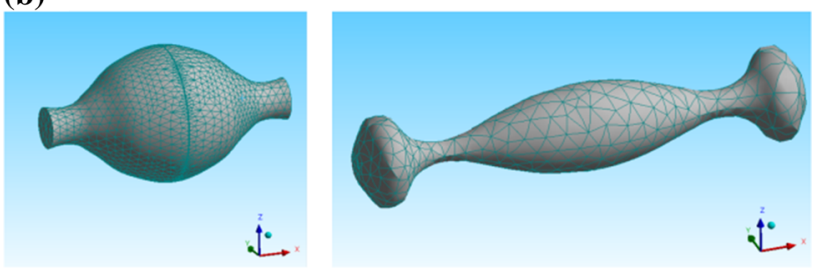

Fig. 2 a Cloud points of elongated and drop shape; $\mathbf{b}$ mesh with triangular elements

after the withdrawal of the rubber itself, allows to reproduce pieces in the size of the original decoration. It is known that the enlargement of the architectural decoration reproduced in the clay (matrix) is carried out empirically and the accuracy achieved in the reproduced architectural elements is left to the experience and intuitive skills of the craftsman to find the correct dimensions of this matrix and the mold. Needless to say that this process often requires several attempts.

In the proposed methodology, the acquisition through Laser scanner (EINSCAN-PRO+, accuracy $\leq 100 \mu \mathrm{m}$ ) allows to obtain the point cloud of architectural decorations (Fig. 2a). The cloud is then discretized through NURBS surface with triangular elements (Fig. 2b).

What is important to notice is that it is the maximum size of the elements $\left(l_{\max }\right)$ which determines the accuracy of the reconstruction. In particular, the maximum error between the virtual surface and the real surface of the decoration ( $\max _{\mathrm{err}}$ ) can be assessed through the empirical expression:

$\max _{\text {err }} \leq \frac{l_{\max }}{3}$

Volumetric shrinkage coefficients were evaluated through experimental tests carried out on test pieces with a parallelepiped shape in clay (Colorobbia) and silicone (SILASTIC 3487 base and hardener SILASTIC 87-S) with dimensions similar to those of the decorations. Simulations in FE environment then allowed to obtain the linear shrinkage coefficients along the three main directions for a prismatic cassette mold (Fig. 3).

In Table 1 the volumetric and linear values of withdrawal coefficients are reported.

\section{Results}

By applying the values of the shrinkage coefficients to the virtual geometries of the decorations in the FE simulation 


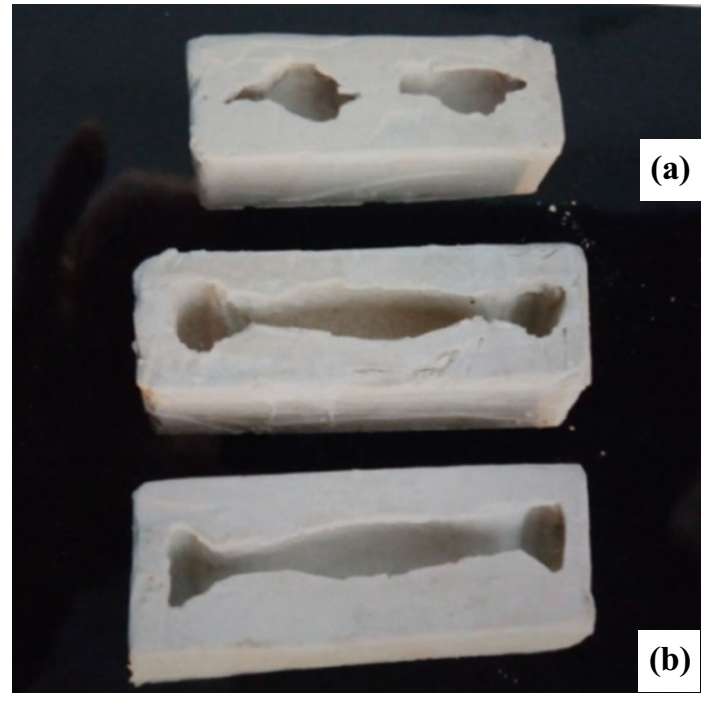

Fig. 3 Sample with parallelepiped shape, a clay; $\mathbf{b}$ silic
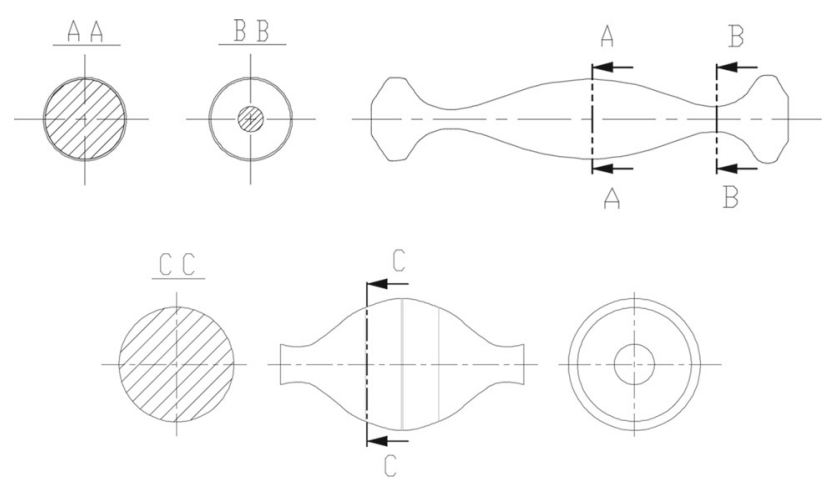

Fig. 4 Geometry of correct sized mold obtained through the profiles of subsequent section

environment, it was possible to evaluate with accuracy the enlargement to be assigned to the matrix to obtain the correct sized mold (Fig. 4). The use of virtual geometric models also allowed an easy reconstruction of any gaps in the decoration.

The matrix was made using RP techniques using $\mathrm{ABS}^{\circledR}$, characterized by very small shrinkages and insensitivity to temperature changes. The silicone elastomer mold derived from the matrix. In particular, high strength silicone rubber (SILASTIC 3487-SILASTIC 87-S) (Table 1) was used, with high mechanical properties, high fidelity to the reproduction of objects, high elasticity, tear resistance and non-stick effect.

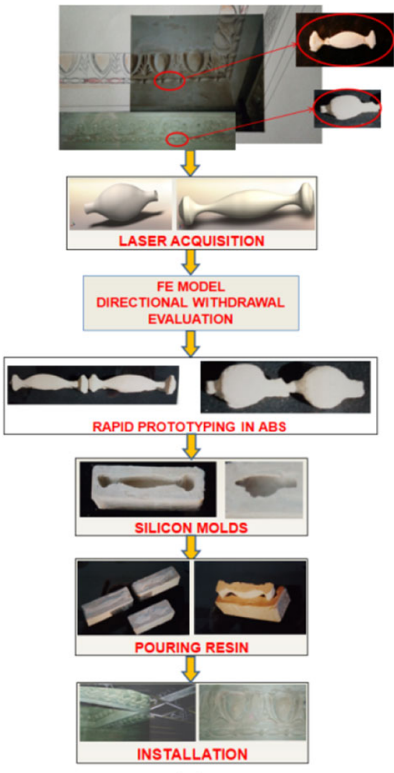

(a)

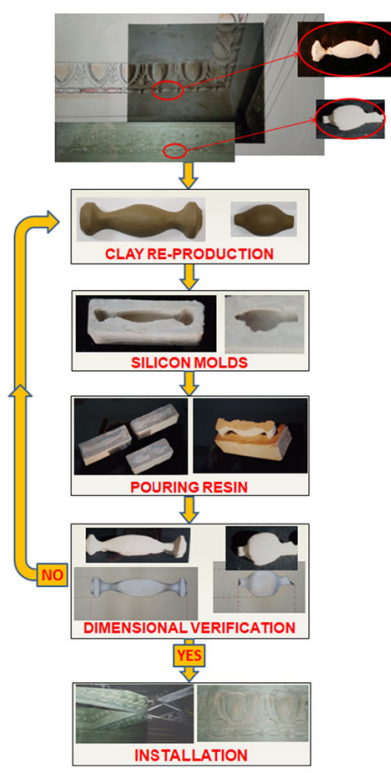

(b)
Fig. 5 a Workflow of proposal methodology; $\mathbf{b}$ workflow of traditional method

The final realization of the decorations took place through the synthetic DIPLAST ${ }^{\circledR}$ resin $(99.9 \%$ biological plaster) characterized by almost zero shrinkage values. As a waterproof material, particularly resistant to humidity (unlike gypsum plaster). DIPLAST resin is a synthetic gypsum powder that is mixed with water in a stoichiometric ratio and characterized by extra white colouring and strong mechanical resistance. By casting the resin guarantees a perfect replica of the original piece without any deformation or shrinkage. In detail, the casting of this resin is totally non-toxic; mixed in specific ratios in terms of weight with cold water it generates a finished product similar to porcelain, ensuring rapid hardening in 6-10 min without cooking. The restoration work was completed with the installation of the elements carried out through the fixing of threaded steel bars inserted inside the ornaments to adhere with the two-component white polyester adhesive in the coffered roof ensuring effective adhesion once hardened. The described method can also be extended to decorative elements characterized by cavities and undercuts. The proposed methodology allowed a reduction of working times and the achievement of the desired accuracy. In Fig. 5, the workflow of the proposed methodology is schematized, while
Table 1 Volumetric and linear withdrawal coefficients

\begin{tabular}{lllll}
\hline & Vol. withdrawal $(\%)$ & $\begin{array}{l}\text { Linear withdrawal in } \\
x \text { direction }(\%)\end{array}$ & $\begin{array}{l}\text { Linear withdrawal in } \\
y \text { direction }(\%)\end{array}$ & $\begin{array}{l}\text { Linear withdrawal in } \\
z \text { direction }(\%)\end{array}$ \\
\hline Silic & $0.0 \div 0.02$ & $0.05 \div 0.1$ & $0.185 \div 0.2$ & $0.25 \div 0.3$ \\
Clay & $1.5 \div 2.0$ & $3.5 \div 4.0$ & $5.4 \div 5.0$ & $7.7 \div 8.0$ \\
\hline
\end{tabular}


Fig. 5b shows the traditional method based on numerous iterations.

\section{Conclusions}

In this study a methodology for improving the reconstruction method of decorum in architectural surfaces and sculpture was proposed. The analysis focused on the evaluation of the effects of withdrawal caused by catalysis of mold in silicone which were simulated by a NURBS-based solid modelling. A tolerance analysis model was developed to predict manufacturing precision levels. The procedure used was tested through the reconstruction of the missing pieces of the coffered ceiling of the main $21 \mathrm{~m}$ high lobby of Teatro Massimo Vittorio Emanuele in Palermo. The proposed methodology allowed the reconstruction of decorations or fragments of decoration with high accuracy.

Funding Open access funding provided by Università degli Studi di Catania within the CRUI-CARE Agreement.

Open Access This article is licensed under a Creative Commons Attribution 4.0 International License, which permits use, sharing, adaptation, distribution and reproduction in any medium or format, as long as you give appropriate credit to the original author(s) and the source, provide a link to the Creative Commons licence, and indicate if changes were made. The images or other third party material in this article are included in the article's Creative Commons licence, unless indicated otherwise in a credit line to the material. If material is not included in the article's Creative Commons licence and your intended use is not permitted by statutory regulation or exceeds the permitted use, you will need to obtain permission directly from the copyright holder. To view a copy of this licence, visit http://creativecomm ons.org/licenses/by/4.0/.

\section{References}

1. Gherardini, F., Santachiara, M., Leali, F.: 3D virtual reconstruction and augmented reality visualization of damaged stone sculptures. IOP Conf. Ser. Mater. Sci. Eng. 364(1), 012-018 (2018)

2. Tang, P., Huber, D., Akinci, B., Lipman, R., Lytle, A.: Automatic reconstruction of as-built building information models from laserscanned point clouds: a review of related techniques. Autom. Constr. 19(7), 829-843 (2010)

3. Egorov, S.B., Kapitanov, A.V., Mitrofanov, V.G., Shvartsburg, L.E., Ivanova, N.A., Ryabov, S.A.: Modern digital manufacturing technical support centers. Int. Electron. J. Math. Educ. 11(7), 2213-2225 (2016)

4. Calì, M., Ambu, R.: Advanced 3D photogrammetric surface reconstruction of extensive objects by UAV camera image acquisition. Sensors 18(9), 2815 (2018)

5. Chaney, D.S.: Mold making with room temperature vulcanizing silicone rubber. Paleontol. Soc. Spec. Publ. 4, 284-304 (1989)

Publisher's Note Springer Nature remains neutral with regard to jurisdictional claims in published maps and institutional affiliations. 